\title{
Copper-Catalyzed Synthesis of Hindered Ethers from $\alpha-$ Bromo Carbonyl Compounds
}

\author{
Zhe Zhou, † Nicole Erin Behnkeł and László Kürti* \\ Department of Chemistry, Rice University BioScience Research Collaborative 650o Main Street, Rm 38o, Houston, \\ TX 77030 (USA) E-mail: kurti.laszlo@rice.edu
}

ABSTRACT: A catalytic method for the synthesis of sterically-hindered ethers and thioethers from $\alpha$-bromo carbonyl compounds and the corresponding nucleophiles using an inexpensive $\mathrm{Cu}(\mathrm{I})$ catalytic system is reported. This facile transformation takes place at ambient temperature and does not require the exclusion of air or moisture; thus, it is well-suited for the functionalization and derivatization of complex organic molecules.

The ether linkage is a ubiquitous structural motif in natural products and active pharmaceutical ingredients. ${ }^{1}$ Due to its importance and frequent occurrence, synthetic methodologies that target ethers have seen significant advancements in recent years. ${ }^{2}$ However, currently, there are still challenges in the syntheses of certain classes of ethers, especially those with hindered ( $3^{\circ}$ or $2^{\circ}$ ) alkyl groups. A survey of the existing synthetic strategies for ethers reveals their inadequacies (Figure 1): (A) the Williamson ether synthesis suffers when hindered nucleophiles and/or electrophiles are involved; ${ }^{3}$ (B) the Ullmann coupling is only applicable for the synthesis of biaryl ethers; ${ }^{4}(\mathrm{C})$ copper(II)and palladium-catalyzed ether synthesis (Chan-Lam coupling and Buchwald-Hartwig coupling, respectively) generally can only make ethers with at least one aryl group; ${ }^{5}$ (D) the hydroalkoxylation of alkenes also suffers from the limitation caused by steric hindrance, and most examples of tertiary ether formation with this strategy are limited to intramolecular examples. ${ }^{6}$

Synthesizing tertiary alkyl ethers is especially difficult, and generally requires either strongly acidic conditions or the prolonged heating of substrates in the presence of a strong base. Neither condition is ideal for delicate substrates that are often found as intermediates in natural product total synthesis and medicinal chemistry. Barton pioneered the use of aryl bismuth reagents to form aryl ethers under $\mathrm{Cu}(\mathrm{II})$ catalysis, $^{7}$ and Mukaiyama later optimized this methodology to form aryl/tertiary alkyl ethers using bismuth $(\mathrm{V})$ reagents. ${ }^{8}$ However, the substrate scope for these types of reactions is still quite limited and the required aryl bismuth reagents are often difficult to obtain. The use of diaryliodonium salts in the syntheses of hindered ethers has also been reported, ${ }^{9}$ although currently the transferable aryl groups are limited to either electron-deficient or sterically hindered aromatic rings. Recently, a C-H etherification reaction reported by the Warren group demonstrated a promising new strategy in this research area. ${ }^{10}$ However, the requirement for a large excess (20 equiv) of the alkyl coupling partner could potentially hinder its efficient utilization. The formation of bis-tertiary alkyl ethers remains one of the most difficult challenges, for which no general methods are currently available. Starting our investigation, we quickly realized that the steric bulkiness of the tertiary alkyl groups creates a major obstacle.

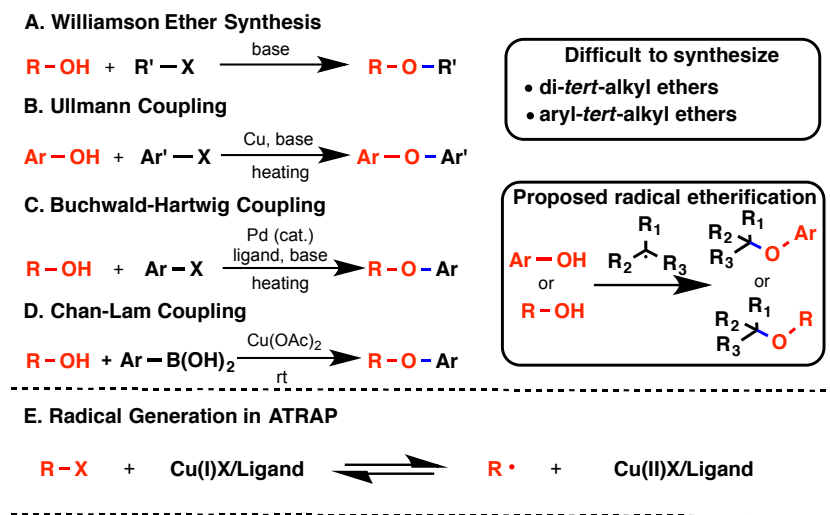

F. Proposed Reaction Design Based on ATRAP

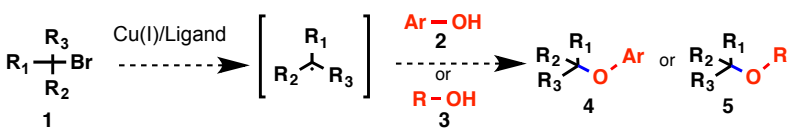

Figure 1. Existing etherification methods and the initial design for radical etherification

To overcome this issue, we considered the use of radicals, as steric effects tend to have less impact on their reactivity when compared to other reactive intermediates." We started our investigation with a search for a catalytic system that can readily generate tertiary alkyl radicals. In polymer science, a commonly employed strategy is the atom transfer radical addition polymerization (ATRAP), which generates radicals from alkyl bromides with transition metal catalysts. ${ }^{12}$ Since its discovery in 1995, successful attempts have been made by organic chemists to exploit this 
strategy in the syntheses of small molecules. ${ }^{13}$ To the best of our knowledge, this strategy has not been used in etherification. Herein, we report the results of our investigation. We carried out the initial trials with fully substituted $\alpha$ bromo carboxylates (Table 1: entry 1 \& 2). No ether products were observed. We rationalized this result with the apparent lower reactivity of alcohols and phenols compared to styrenes. ${ }^{13 a, 13 e}$ However, a small amount of the ether was obtained when amide $8 \mathbf{a}$ was used (Table 1: entry 4). Encouraged by this initial result, further optimizations were carried out (Table 1 ).

Table 1. Reaction Conditions Optimization for the Etherification of $\alpha$-bromo carbonyl compounds.

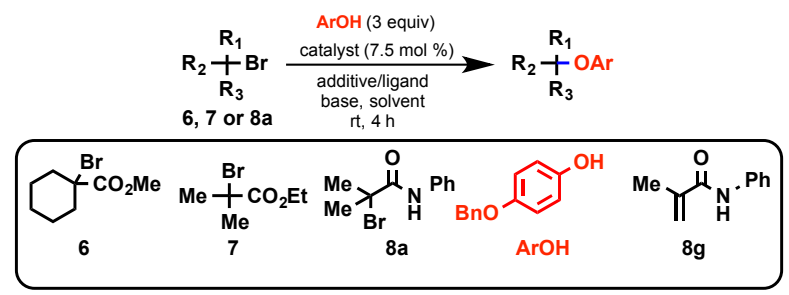

\begin{tabular}{|c|c|c|c|c|c|c|}
\hline entry $^{[a]}$ & $\mathrm{RBr}$ & catalyst & additive/ligand & base & solvent & yield \\
\hline 1 & 6 & $\mathrm{CuBr} \cdot \mathrm{SMe}_{2}$ & PMDETA (1 equiv) & $\mathrm{TBABr}$ & toluene & $N R^{b}$ \\
\hline 2 & 7 & $\mathrm{CuBr} \cdot \mathrm{SMe}_{2}$ & PMDETA (1 equiv) & $\mathrm{TBABr}$ & toluene & $N R^{b}$ \\
\hline 3 & $8 a$ & $\mathrm{CuBr} \cdot \mathrm{SMe}_{2}$ & PMDETA (1 equiv) & $\mathrm{TBABr}$ & toluene & $N R^{b}$ \\
\hline 4 & $8 a$ & $\mathrm{CuBr} \cdot \mathrm{SMe}_{2}$ & PMDETA (1 equiv) & $\mathrm{K}_{3} \mathrm{PO}_{4}$ & toluene & $5 \%{ }^{b}$ \\
\hline 5 & $8 a$ & $\mathrm{CuBr} \cdot \mathrm{SMe}_{2}$ & $\mathrm{PPh}_{3}(10 \mathrm{~mol} \%)$ & $\mathrm{K}_{3} \mathrm{PO}_{4}$ & toluene & $24 \%$ \\
\hline 6 & $8 a$ & $\mathrm{CuBr} \cdot \mathrm{SMe}_{2}$ & $\mathrm{PPh}_{3}(10 \mathrm{~mol} \%)$ & $\mathrm{K}_{3} \mathrm{PO}_{4}$ & $\mathrm{MeCN}$ & $48 \%$ \\
\hline 7 & $8 a$ & $\mathrm{Co}(\mathrm{acac})_{3}$ & $\mathrm{PPh}_{3}(10 \mathrm{~mol} \%)$ & $\mathrm{K}_{3} \mathrm{PO}_{4}$ & $\mathrm{MeCN}$ & $<10 \%$ \\
\hline 8 & $8 a$ & $\mathrm{Fe}(\mathrm{acac})_{3}$ & $\mathrm{PPh}_{3}(10 \mathrm{~mol} \%)$ & $\mathrm{K}_{3} \mathrm{PO}_{4}$ & $\mathrm{MeCN}$ & $30 \%$ \\
\hline 9 & $8 a$ & none & $\mathrm{PPh}_{3}(10 \mathrm{~mol} \%)$ & $\mathrm{K}_{3} \mathrm{PO}_{4}$ & $\mathrm{MeCN}$ & Trace \\
\hline 10 & $8 a$ & $\mathrm{CuBr} \cdot \mathrm{SMe}_{2}$ & $\mathrm{P}(2 \text {-furyl })_{3}(10 \mathrm{~mol} \%)$ & $\mathrm{K}_{3} \mathrm{PO}_{4}$ & $\mathrm{MeCN}$ & $44 \%$ \\
\hline 11 & $8 a$ & $\mathrm{CuBr} \cdot \mathrm{SMe}_{2}$ & DPPF (10 mol \%) & $\mathrm{K}_{3} \mathrm{PO}_{4}$ & $\mathrm{MeCN}$ & $22 \%$ \\
\hline 12 & $8 a$ & $\mathrm{CuBr} \cdot \mathrm{SMe}_{2}$ & $\mathrm{PCy}_{3}(10 \mathrm{~mol} \%)$ & $\mathrm{K}_{3} \mathrm{PO}_{4}$ & $\mathrm{MeCN}$ & $87 \%$ \\
\hline 13 & $8 a$ & $\mathrm{CuBr} \cdot \mathrm{SMe}_{2}$ & none & $\mathrm{K}_{3} \mathrm{PO}_{4}$ & $\mathrm{MeCN}$ & $\mathrm{NR}^{\mathrm{c}}$ \\
\hline 14 & 7 & $\mathrm{CuBr} \cdot \mathrm{SMe}_{2}$ & $\mathrm{PCy}_{3}(10 \mathrm{~mol} \%)$ & $\mathrm{K}_{3} \mathrm{PO}_{4}$ & $\mathrm{MeCN}$ & $N^{c}$ \\
\hline
\end{tabular}

[a] Reactions were conducted on a $0.2 \mathrm{mmol}$ scale. Amide (1 equiv), phenol (3 equiv), catalyst $(7.5 \mathrm{~mol} \%)$, base ( 1.2 equiv) and ligand/additive were mixed in $0.5 \mathrm{~mL}$ solvent and stirred at rt for $4 \mathrm{~h}$. [b] The reactions were carried out at $4 \mathrm{o}^{\circ} \mathrm{C}$. [c] Significant amount of elimination was observed.

A milder base $\left(\mathrm{K}_{3} \mathrm{PO}_{4}\right)$ effectively promoted the nucleophilic attack while minimizing side reactions caused by elimination (Table 1: entry 4). A phosphine ligand drastically improved the reaction outcome, albeit with a relatively low turnover number (Table 1: entry 5 ). The reaction occurs in both polar and non-polar solvents, with acetonitrile being the best to achieve a fast reaction rate at ambient temperature (Table 1: entry 6, also see Supporting
Information). Other metals (i.e. cobalt and iron) also catalyzed the reaction, although not as efficiently as $\mathrm{Cu}(\mathrm{I})$ (Table 1: entries 7-8). While several phosphines can facilitate the reaction, $\mathrm{PCy}_{3}$ was found to be the most effective (Table 1 : entry 10-12). The reaction does not yield an ether product in the absence of a ligand, and the acrylamide $8 \mathrm{~g}$ resulting from the elimination was observed as the only major product (Table 1 : entry 13). In the absence of copper, only a trace amount of the ether product was detected

Scheme 1. The Formation of Hindered Ethers from $\alpha-$ Bromo Carboxamides 


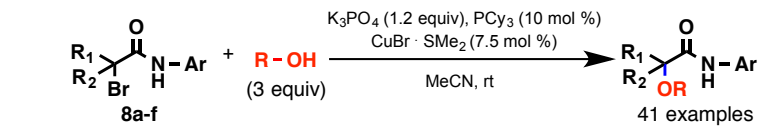

Structures of Hindered Ether and Thioether products from $\alpha$-Bromo Carboxamides Compound \#[a], Isolated Yield (\%)

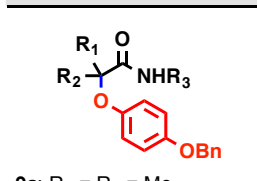

9a: $\mathrm{R}_{1}=\mathrm{R}_{2}=\mathrm{Me}$

$\mathrm{R}_{3}=\mathrm{Ph}, 87 \%$

$(73 \%$ at $5 \mathrm{mmo}$
$\mathrm{R}_{1}=\mathrm{R}_{2}=\mathrm{Me}$,

$R_{3}=1-N a p h, 80 \%$

9c: $\mathrm{R}_{1}, \mathrm{R}_{2}=\left(\mathrm{CH}_{2}\right)_{5}$

$R_{3}=\mathrm{Ph}, 35 \%$

$\mathbf{R}_{1}$ O

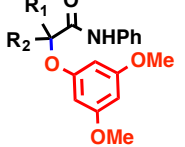

OMe

12a: $R_{1}=R_{2}=M e, 57 \%$

12b: $R_{1}, R_{2}=\left(\mathrm{CH}_{2}\right)_{4}, 31 \%$

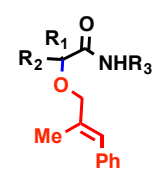

15a: $R_{1}=R_{2}=M e, R_{3}=$

4-Ethoxycarbonylphenyl, 65\%

15b: $\mathrm{R}_{1}, \mathrm{R}_{2}=\left(\mathrm{CH}_{2}\right)_{5}, \mathrm{R}_{3}=\mathrm{Ph}, 53 \%$

16a:

政,

$=\mathrm{R}_{2}=\mathrm{Me}$

$\mathrm{R}_{3}=4$-Ethoxycarbonylphenyl, $44 \%^{\mathrm{c}}$ 16c: $R_{1}, R_{2}=\left(\mathrm{CH}_{2}\right)_{5}, R_{3}=P h, 27 \% c$

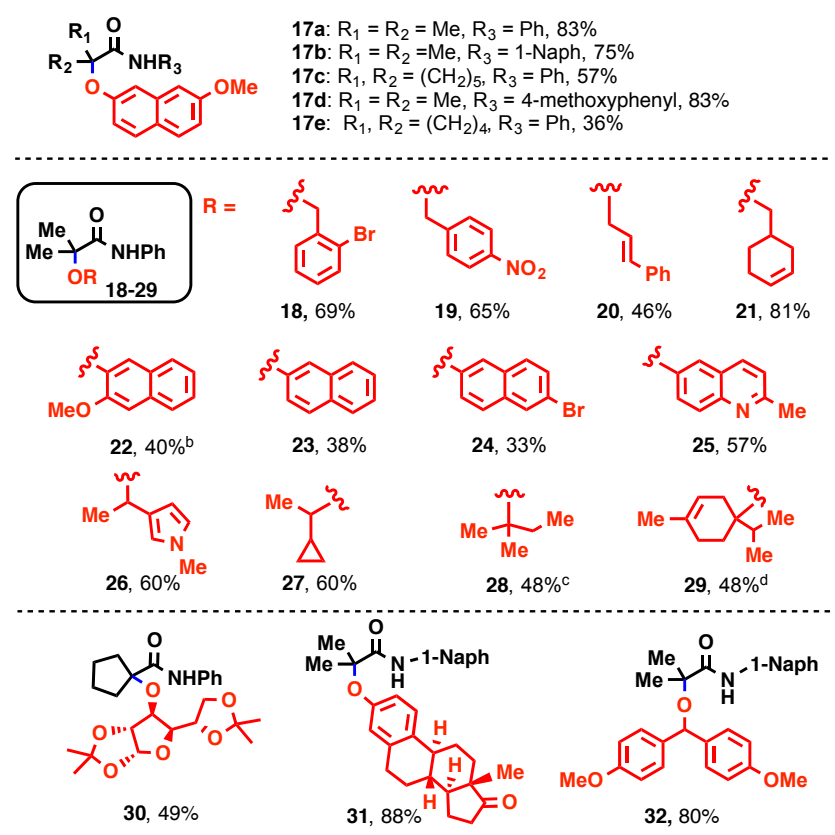

[a] Reaction conditions: carboxamide (o.2 mmol), $\mathrm{CuBr} . \mathrm{SMe}_{2}(7.5 \mathrm{~mol} \%), \mathrm{PCy}_{3}$ (10 mol \%), $\mathrm{K}_{3} \mathrm{PO}_{4}$ (1.2 equiv), and alcohol/phenol (3 equiv) were mixed in $\mathrm{MeCN}$ at room temperature. [b] Reaction performed with $\mathrm{PPh}_{3}$ instead of $\mathrm{PCy}_{3}$. [c] Reaction performed at $50^{\circ} \mathrm{C}$ for $24 \mathrm{~h}$. [d] Reaction performed at $80{ }^{\circ} \mathrm{C}$ for $24 \mathrm{~h}$.

(Table 1: entry 9). Reactions generally reached completion after $4 \mathrm{~h}$, and were conducted without the exclusion of moisture or air. A control experiment under argon gave virtually the same results. Interestingly, even with the optimized conditions, the reaction still did not proceed in the absence of a secondary amide (Table 1 : entry 14). These observations were generally consistent with reports by Nishikata et al. in the context of amine synthesis. ${ }^{13 \mathrm{C}}$

Next, we explored the reaction scope with various phenols and alcohols (Scheme 1). The conditions worked well with primary alcohols and electron-rich phenols, and the corresponding ethers were obtained in good to excellent yields at room temperature. Interestingly, styrenyl olefins were unaffected under the reaction conditions (Scheme 1: 15 and 20), which is unexpected for the radical-based mechanism. Electron-rich phenols worked as well as primary alcohols. Electron-neutral and electron-deficient phenols generally gave lower yields of the corresponding ethers (Scheme 1: 23 \& 24) and very electron-deficient phenols such as 4-nitrophenol failed to participate in the reaction. For the amide portion of the substrates, various arylamines were tolerated, and the electronic properties of the aryl group did not have a significant influence on the reaction outcomes (Scheme 1: 15a vs. 15b; 17a vs. $17 \mathbf{d}$ ). Dialkyl substitutions in the $\alpha$-position of the amides were also well-tolerated. Aside from $\alpha$-bis-methyl substitution, the reaction also worked well with carboxamides containing cyclohexane and cyclopentane substituents. The conditions tolerated various functional groups, and even a densely functionalized phenol such as estrone participated in the reaction and furnished the desired ether in an excellent isolated yield (Scheme 1:31). It was observed that for phenols with an ortho substituent, $\mathrm{PPh}_{3}$ is a superior ligand (Scheme 1: 10a, 10c \& 22). For primary alcohols, similar yields were obtained when the amount of the alcohol coupling partner was reduced to two equivalents. However, a significant drop in yields occurred when the number of equivalents of phenols was reduced (see SI). The reaction also scaled up nicely without a significant drop in efficiency and, in one instance, the isolated yield increased slightly (See Scheme 1: 9a and 11a).

Scheme 2. Synthesis of an Analogue of PAR-1 Antagonist.

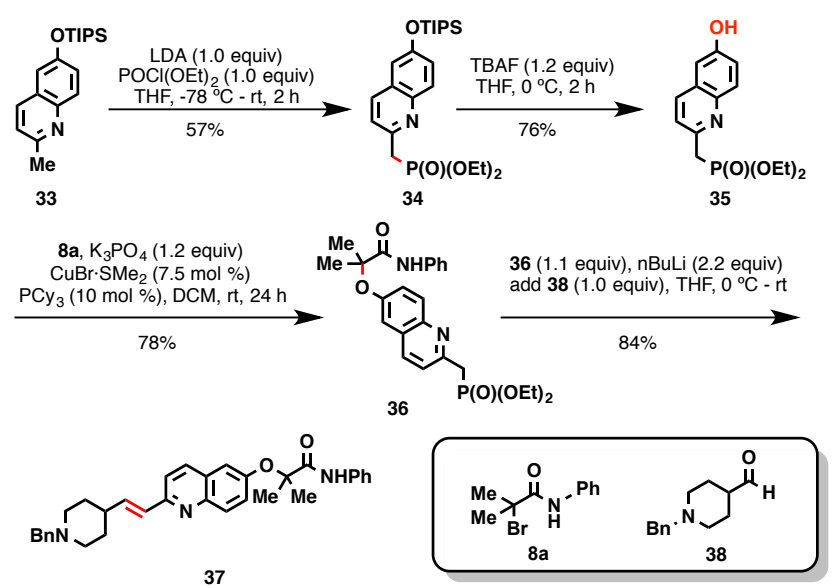

Next, we attempted more challenging etherifications with sterically hindered secondary and tertiary alcohols. Most secondary alcohols participated in the reaction and gave good to excellent yields of the corresponding ethers 
(Scheme 1: 13-14, 26-27, 30 and 32). Tertiary alcohols did not react at room temperature. However, upon elevating the reaction temperature, synthetically useful yields of the bis-tert-alkyl ethers were obtained after $24 \mathrm{~h}$ (Scheme 1: 16 and 28-29). The yields are lower than those of the less hindered nucleophiles, although it should be noted that such transformations were unprecedented and, to the best of our knowledge, none of the resulting ethers have ever been reported. Heterocyclic rings were also well-tolerated in this reaction (Scheme 1: 25-26). The reaction conditions' mildness was further demonstrated with the successful etherification of a furanose derivative bearing acid-labile functionalities (Scheme 1: 30).

Scheme 3. Investigation of the mechanism
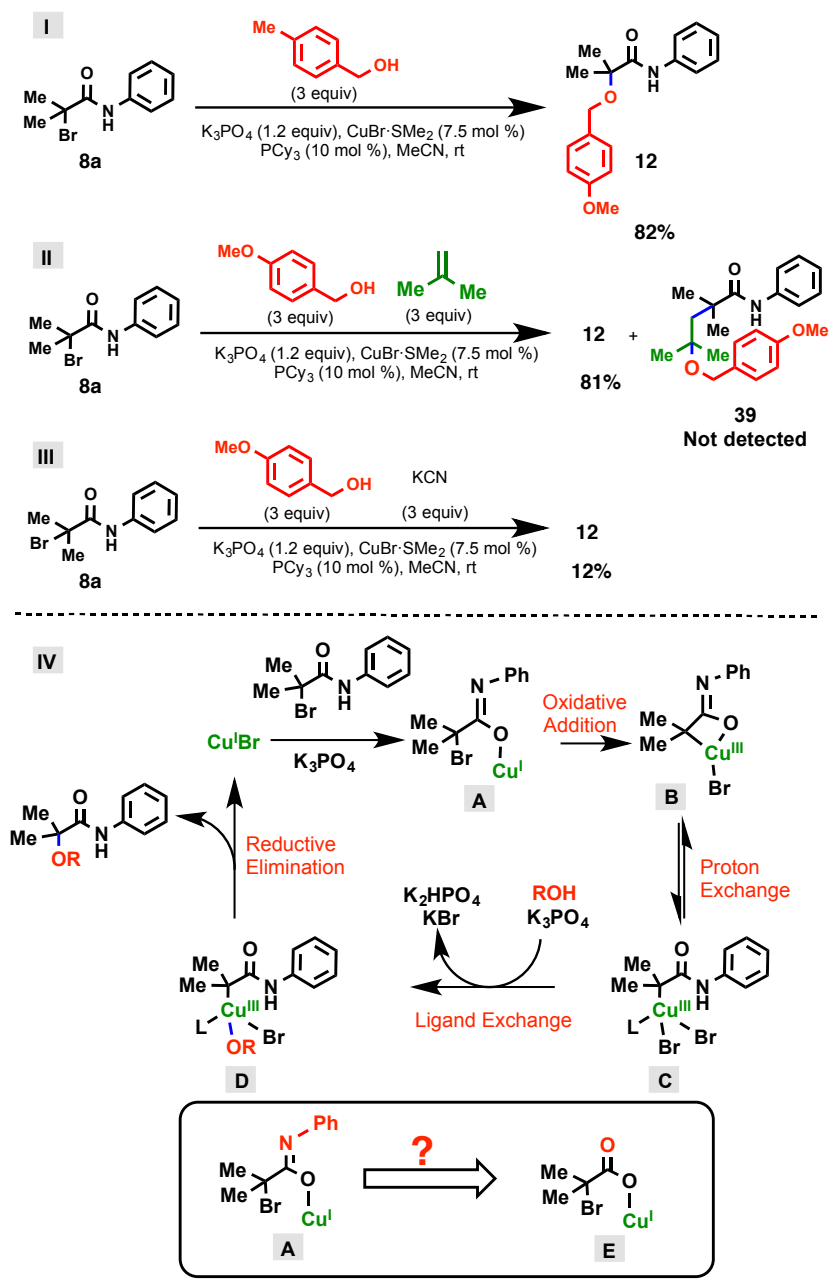

The reaction conditions' tolerance toward a wide range of functional groups enables the development of more efficient routes toward medicinal chemistry targets, as demonstrated in Scheme 2. Phosphonate $\mathbf{3 6}$ can be synthesized via this new route to serve as a common intermediate for a series of PAR-1 antagonists, while previously, the alkene building blocks had to be synthesized individually due to the harsh conditions required for etherification. ${ }^{14}$

Despite being important building blocks in organic synthesis, amides are not always ideal for further functionalization. In our attempts, amides resisted reduction even with strong reductants such as $\mathrm{LiAlH}_{4}$, and the reaction yields were low even after prolonged reaction time (See SI). Therefore, this method will be much more advantageous if it can be extended to other carbonyl compounds. To achieve this goal, we took a closer look at the mechanism.

Although we started this study with the assumption of a radical-based mechanism, several of our observations do not lend support to it. As mentioned before, no C-C bond formation with styrenes or phenols was observed in these reactions, whereas such side reactions should be expected from a process that involves carbon-centered radicals. ${ }^{15}$ To probe the reaction mechanism, further investigations were carried out (Scheme 3 ). In the presence of 3 equivalents of isobutylene, the reaction proceeded normally and gave a nearly identical yield of the ether without generating any product from isobutylene trapping (Scheme 3: I vs II). In the presence of 3 equivalents of $\mathrm{KCN}$, the reaction was greatly inhibited and only $12 \%$ yield of the ether was obtained (Scheme 3: III). Most importantly, the reaction did not proceed when the amide functionality was absent, an observation that cannot be adequately explained by a mechanistic hypothesis based on a radical process.

Scheme 4. The Formation of Hindered (Thio)ethers from $\alpha$-Bromo Carboxylic Acids

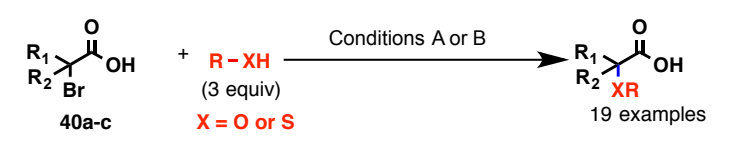

Structures of Hindered Ethe/Thioether Products from $\alpha$-Bromo Carboxylic Acids Compound \#, Isolated Yield (\%)
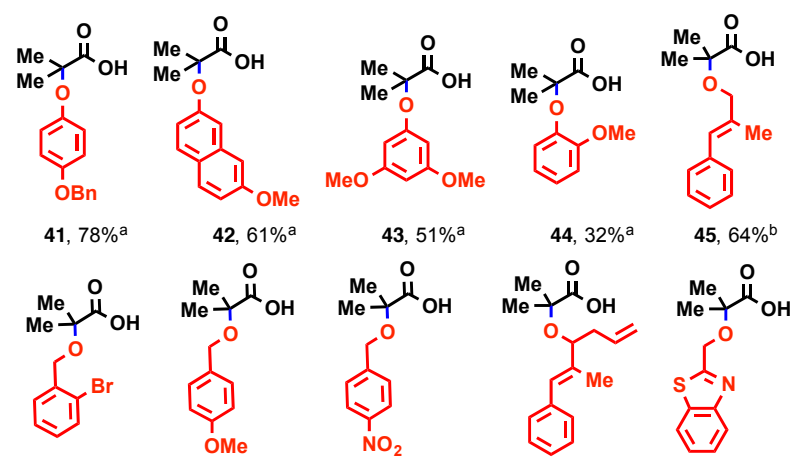

$45,64 \%$ b

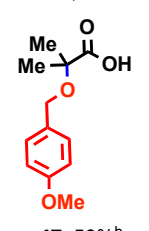

$48,58 \%$ b

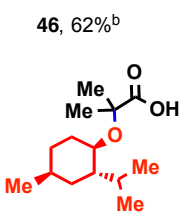

$47,56 \%$ b
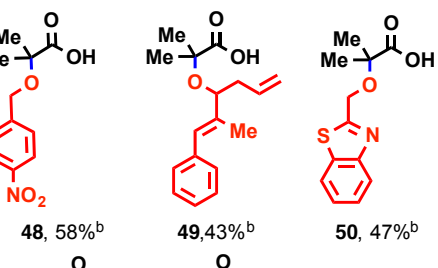

$50,47 \%$ b
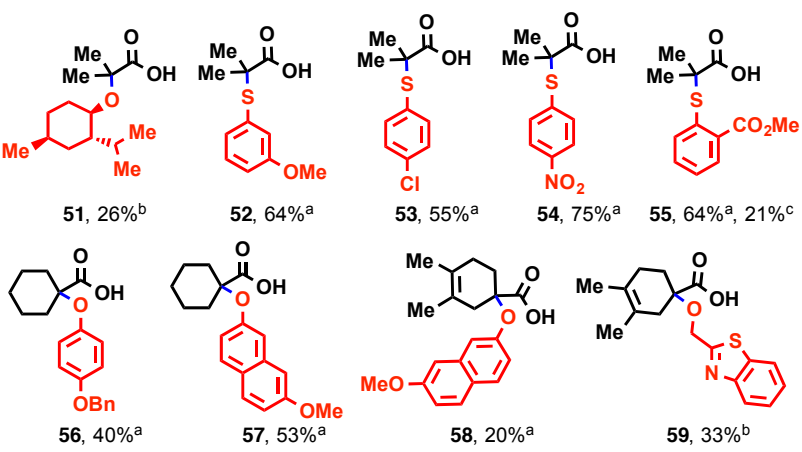

$54,75 \%^{a} \quad 55,64 \%^{a}, 21 \%^{c}$

[a] Reaction conditions A: carboxylic acids (0.4 mmol), $\mathrm{CuBr} \mathrm{SMe}_{2}$ (2.5 mol \%), $\mathrm{PCy}_{3}$ (3.5 mol \%), $\mathrm{K}_{3} \mathrm{PO}_{4}$ (1.2 equiv), and alcohol/phenol (3 equiv) were reacted in $2 \mathrm{~mL} \mathrm{DCM}$ at 
room temperature for $16 \mathrm{~h}$. [b] Reaction Conditions B: carboxylic acids (0.4 mmol), CuBr.SMe 2 (7.5 mol \%), $\mathrm{PCy}_{3}$ (10 mol $\%), \mathrm{K}_{3} \mathrm{PO}_{4}$ (1.2 equiv), and alcohol/phenol (3 equiv) were reacted in a mixed solvent of $1 \mathrm{~mL}$ DCM and $1 \mathrm{~mL}$ HFIP at room temperature for $16 \mathrm{~h}$. [c] reaction was ran according to Conditions $\mathrm{A}$ but without $\mathrm{Cu}$ and ligand.

Based on these results, we propose a different mechanism for these reactions: upon deprotonation of the amide $\mathrm{N}-\mathrm{H}$ bond, the copper(I) first coordinates to the oxygen atom of the resulting imino-carboxylate anion (Scheme 3: IV-A), followed by an intramolecular oxidative addition into the tertiary C-Br bond (Scheme 3: IV-B). Ligand exchange followed by reductive elimination generates the ether product and completes the catalytic cycle (Scheme 3: IV-D). We propose that the initial coordination between copper and the amide lowers the activation barrier for oxidative addition and is essential for the success of this reaction; therefore a secondary amide is required for this reaction. Indeed, etherification did not proceed when tertiary amides were used. A cyanide anion slows down the oxidative addition step upon coordination to copper, thus inhibiting the reaction. ${ }^{16}$ Although it is possible that the oxidative addition step involves a radical species (i.e. radical oxidative insertion $){ }^{17}$ it is unlikely that a free radical exists in a significant concentration, given that isobutylene failed to trap the hypothetical radical intermediate. It is noted that in one of their latest reports, the Nishikata group also proposed an oxidative addition/reductive elimination mechanism, although it did not take into consideration the participation of the imino-carboxylate. ${ }^{13 \mathrm{C}}$

Driven by this hypothesis, we anticipated that a structurally-similar intermediate E (Scheme 3: IV) generated from carbocyclic acids should also facilitate the etherification. This prediction came to fruition, as initial trials yielded positive results. After further optimization, moderate to good yields were obtained for a variety of nucleophiles (Scheme 4).

DCM was a better solvent for carboxylic acid substrates, and lower catalyst loading to $2.5 \mathrm{~mol} \%$ improved the reaction yields for phenol and thiophenol nucleophiles (Scheme 4: Conditions A). Initially, we experienced great difficulties attempting to extend the scope of nucleophiles to include simple aliphatic alcohols, as decomposition of the $\alpha$-bromo acids outcompeted the etherification under the reaction conditions. However, upon the addition of HFIP, the side reactions were suppressed and the yields for the ethers greatly improved. The scope of nucleophiles was comparable to that of the amide substrates. Phenols (Scheme 4: 41-44), primary and secondary alcohols (Scheme 4: 45-51 \& 56-59) and thiophenols (Scheme 4: 5255) were successfully coupled with the $\alpha$-bromo acids. It was observed that the uncatalyzed reactions between thiophenols and $\alpha$-bromo acids could proceed, albeit with much lower yields (Scheme 4: 55). Due to the accelerated decomposition of the carboxylic acids upon heating, we were unable to make bis-tertiary ethers with satisfactory yields. The carboxylic acid products provide ample opportunities for further modification, as they can be easily con- verted to esters, amides, aldehydes, and alcohols. Furthermore, these functionalized carboxylic acids can potentially serve as coupling partners in various decarboxylative coupling reactions. ${ }^{18}$

In conclusion, we have developed an efficient method for the synthesis of sterically congested ethers and thioethers. This scalable transformation proceeds at ambient temperature and is tolerant toward air and moisture. We anticipate that this method will benefit the field of medicinal chemistry and chemical biology, where hindered ethers are commonly found as structural motifs in biologically-active molecules and small molecule probes, yet no general synthetic tools have been available for their synthesis. Currently, studies are underway to further probe the reaction mechanism and expand the reaction scope.

\section{ASSOCIATED CONTENT}

\section{Supporting Information}

The Supporting Information is available free of charge on the ACS Publications website.

Experimental details, characterizations of compounds and NMR spectra. (PDF)

\section{AUTHOR INFORMATION}

\section{Corresponding Author}

* E-mail: kurti.laszlo@rice.edu

\section{Author Contributions}

$\$$ These authors contributed equally.

\section{Funding Sources}

Rice University

National Institutes of Health (Ro1 GM-114609-01)

National Science Foundation (CAREER:SusChEM CHE-

1546097)

Robert A. Welch Foundation (Grant C-1764), ACS-PRF

(Grant 51707-DNI1)

\section{ACKNOWLEDGMENT}

The authors thank Dr. Andras Toro (Rice University \& Baylor College of Medicine) for helpful discussions.

\section{ABBREVIATIONS}

PMDETA, $N, N, N^{\prime}, N^{\prime \prime}, N^{\prime \prime}$-Pentamethyldiethylenetriamine; $\mathrm{TBABr}$, tetrabutylammonium bromide; DPPF, 1,1' $\mathbf{1}^{\prime}$-Ferrocenediyl-bis(diphenylphosphine); PAR-1, protease-activated receptor-1; LDA, lithium diisopropylamide; TBAF, tetrabutylammonium fluoride; HFIP, hexafluoroisopropanol;

\section{REFERENCES}

1. Feuer, H.; Hooz, J., Methods of formation of the ether linkage. In The Ether Linkage (1967), John Wiley \& Sons, Ltd.: 2010; pp 445498.

2. (a) Ley, S. V.; Thomas, A. W., Angew. Chem. Int. Ed. 2003, 42, 5400-5449; (b) Frlan, R.; Kikelj, D., Synthesis 2006, 2271-2285. 
3. For a recent review, see: (a) Fuhrmann, E.; Talbiersky, J., Org. Process Res. Dev. 2005, 9, 206-211; for some representative example, see: (b) Masada, H.; Gotoh, H.; Ohkubo, M., Chem. Lett. 1991, 20, 1739-1742. (c) Shibatomi, K.; Kotozaki, M.; Sasaki, N.; Fujisawa, I.; Iwasa, S., Chem. Eur. J. 2015, 21, 14095-8.

4. For recent reviews, see: (a) Kunz, K.; Scholz, U.; Ganzer, D., Synlett 2003, 2428-2439; (b) Sambiagio, C.; Marsden, S. P.; Blacker, A. J.; McGowan, P. C., Chem. Soc. Rev. 2014, 43, 3525-3550; for some representative examples, see: (c) Naidu, A. B.; Jaseer, E. A.; Sekar, G., J. Org. Chem. 2009, 74, 3675-3679; (d) Sugata, H.; Tsubogo, T.; Kino, Y.; Uchiro, H., Tetrahedron Lett. 2017, 58, 10151019.

5. For recent reviews, see: (a) Qiao, J. X.; Lam, P. Y. S., Synthesis 2011, 829-856; (b) Evano, G.; Blanchard, N.; Toumi, M., Chem. Rev. 2008, 108, 3054-3131; (c) Muzart, J., Tetrahedron 2005, 61, 59556oo8; (d) Hartwig, J. F., Angew. Chem. Int. Ed. 1998, 37, 2046-2067; (e) Hartwig, J. F., Acc. Chem. Res. 1998, 31, 852-86o; for an example with sterically hindered diaryl ethers, see: (f) Burgos, C. H.; Barder, T. E.; Huang, X.; Buchwald, S. L., Angew. Chem. Int. Ed. 2006, 45, 4321-6.

6. For recent reviews, see: (a) Hintermann, L., Recent Developments in Metal-Catalyzed Additions of Oxygen Nucleophiles to Alkenes and Alkynes. In $C-X$ Bond Formation, Vigalok, A., Ed. Springer Berlin Heidelberg: Berlin, Heidelberg, 2010; pp 123-155; (b) Hanley, P. S.; Hartwig, J. F., Angew. Chem. Int. Ed. 2013, 52, 8510-8525; (c) Rodriguez-Ruiz, V.; Carlino, R.; Bezzenine-Lafollee, S.; Gil, R.; Prim, D.; Schulz, E.; Hannedouche, J., Dalton Trans. 2015, 44, 12029-12059; for an example of intramolecular etherification, see: (d) Hamilton, D. S.; Nicewicz, D. A., J. Am. Chem. Soc. 2012, 134, 18577-18580.

7. Barton, D. H. R.; Bhatnagar, N. Y.; Blazejewski, J.-C.; Charpiot, B.; Finet, J.-P.; Lester, D. J.; Motherwell, W. B.; Papoula, M. T. B.; Stanforth, S. P., J. Chem. Soc., Perkin Trans. 1 1985, 2657.

8. (a) Ikegai, K.; Fukumoto, K.; Mukaiyama, T., Chem. Lett. 2006, 35, 612-613; (b) Mukaiyama, T.; Sakurai, N.; Ikegai, K., Chem. Lett. 2006, 35, 1140-1141; (c) Sakurai, N.; Ikegai, K.; Mukaiyama, T., Arkivoc 2007, 2007, 254-264.
9. Lindstedt, E.; Stridfeldt, E.; Olofsson, B., Org. Lett. 2016, 18, 4234-4237.

10. Salvador, T. K.; Arnett, C. H.; Kundu, S.; Sapiezynski, N. G.; Bertke, J. A.; Raghibi Boroujeni, M.; Warren, T. H., J. Am. Chem. Soc. 2016, 138, 16580-16583.

11. Yan, M.; Lo, J. C.; Edwards, J. T.; Baran, P. S., J. Am. Chem. Soc. 2016, 138, 12692-12714.

12. (a) Kato, M.; Kamigaito, M.; Sawamoto, M.; Higashimura, T., Macromolecules 1995, 28, 1721-1723; (b) Wang, J.-S.; Matyjaszewski, K., J. Am. Chem. Soc. 1995, 117, 5614-5615.

13. (a) Nishikata, T.; Noda, Y.; Fujimoto, R.; Sakashita, T., J. Am. Chem. Soc. 2013, 135, 16372-16375; (b) Nishikata, T.; Ishida, S.; Fujimoto, R., Angew. Chem. Int. Ed. 2016, 55, 10008-10012; (c) Ishida, S.; Takeuchi, K.; Taniyama, N.; Sunada, Y.; Nishikata, T., Angew. Chem. Int. Ed. 2017, 56, 11610-11614; (d) Noda, Y.; Nishikata, T., Chem. Commun. 2017, 53, 5017-5019; (e) Gockel, S. N.; Buchanan, T. L.; Hull, K. L., J. Am. Chem. Soc. 2018, 140, 58-61; (f) Yumi, M.; Takashi, N., Chemistry - A European Journal 2018, 24, 6354-6357.

14. Clasby, M. C.; Chackalamannil, S.; Czarniecki, M.; Doller, D.; Eagen, K.; Greenlee, W. J.; Lin, Y.; Tsai, H.; Xia, Y.; Ahn, H. S.; Agans-Fantuzzi, J.; Boykow, G.; Chintala, M.; Foster, C.; Bryant, M.; Lau, J., Bioorg. Med. Chem. Lett. 2006, 16, 1544-8.

15. Yi, H.; Zhang, G.; Wang, H.; Huang, Z.; Wang, J.; Singh, A. K.; Lei, A., Chem. Rev. 2017, 117, 9016-9085.

16. Fagnou, K.; Lautens, M., Angew. Chem. Int. Ed. 2002, 41, 2647.

17. Jahn, U., Radicals in Transition Metal Catalyzed Reactions? Transition Metal Catalyzed Radical Reactions?: A Fruitful Interplay Anyway. In Radicals in Synthesis III, Heinrich, M.; Gansäuer, A., Eds. Springer Berlin Heidelberg: Berlin, Heidelberg, 2012; pp 323-451.

18. (a) Rodriguez, N.; Goossen, L. J., Chem. Soc. Rev. 2011, 40 , 5030-48; (b) Wei, Y.; Hu, P.; Zhang, M.; Su, W., Chem. Rev. 2017, $117,8864-8907$. 


\section{Insert Table of Contents artwork here}

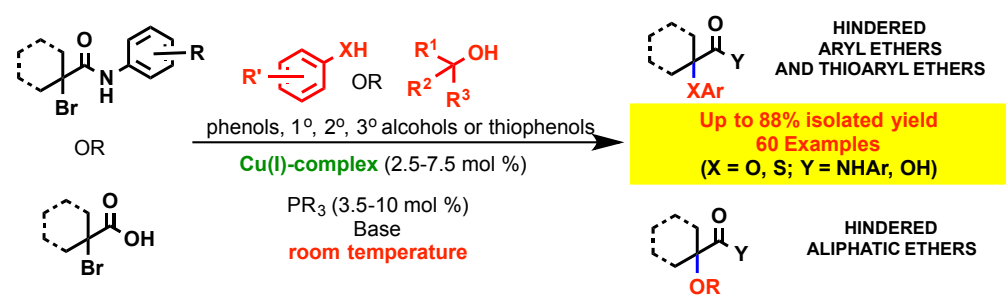

